\title{
SÍSIFO E SUA PEDRA - REFLEXÕES SOBRE O "DIREITO À CIDADE" NO BRASIL EM TEMPOS DE FINANCEIRIZAÇÃO
}

\section{SISYPHUS AND IT STONE - REFLECTIONS ON THE "RIGHT TO CITY" IN BRAZIL IN TIMES OF FINANCIALIZATION}

Tatiana Dahmer Pereira ${ }^{1}$

\section{Resumo}

O ensaio reflete sobre elementos contemporâneos relevantes para se pensar a funcionalidade da produção do urbano a partir dos anos 2000 no Brasil, em contexto de crise estrutural do Capital, refletindo sobre o que aparece como uma dissociação entre direitos como pleitos políticos e lugar da política pública (em especial de Habitação e Saneamento) nas mediações das relações sociais e na sua relação com o direito à cidade. Essa leitura considerou tanto pressupostos como consequências impostas pela absoluta generalização da financeirização da vida em condições propícias nesse modelo "civilizatório", considerando aí os movimentos de uma sociabilidade subordinada à dinâmica do valor, como elemento fundante, o qual impõe ao curso da modernidade a percepção de sua absurdidade construída por Camus (1942) com base no mito de Sísifo.

Palavras chaves: Políticas urbanas - direito à cidade - valor - financeirização

\section{Abstract}

The essay reflects on contemporary relevant elements to think about the functionality of the urban production from the years 2000 in Brazil, in the context of structural crisis of Capital, reflecting on what appears as a decoupling rights as political disputes and place of public policy (in particular housing and sanitation) in the mediation of social relations and their relationship to the right to the city. This reading was considered both assumptions as consequences imposed by absolute generalization of financialization of life conditions in this model "of civilization", considering the movements of a sociability subject to the dynamics of value, its fundamental character, which imposes on the course of modernity the perception of its absurdity built by Camus (1942) based on the myth of Sisyphus.

Keywords: Urban politics - right to the city - value - financialization

\footnotetext{
${ }^{1}$ Doutora e mestre em Planejamento Urbano e Regional pelo Instituto de Pesquisa e Planejamento Urbano e Regional (IPPUR-UFRJ). Professora adjunta da Escola de Serviço Social da Universidade Federal Fluminense (UFF) desde 2009 e docente dos Programas de Mestrado em Serviço Social e Desenvolvimento Regional (PPGSSDR/ESS-UFF). É pesquisadora da Rede QUESS - Questão Urbana e Serviço Social e integra o Núcleo de Estudos e Pesquisa sobre Favelas e Espaços Populares (NEPEF). E-mail: tatianadahmerpereira@gmail.com
} 


\section{APRESENTAÇÃO}

A reflexão teórica aborda a dissociação entre direitos como pleitos políticos e lugar da política pública nas mediações das relações sociais - tendo como emblema políticas de desenvolvimento urbano no Brasil a partir dos anos 2000. Realizamos essa leitura levando em conta o contexto de absoluta generalização da financeirização da vida em condições propícias nesse modelo "civilizatório". Consideramos ser imprescindível problematizar a dinâmica que engendra e norteia o desenho das políticas públicas, na medida em que o Estado capitalista encontra-se tensionado pela crise estrutural de produção do valor ${ }^{2}$ e pela busca desesperada de extração do mesmo, ainda (e paradoxalmente) que por sua dimensão especulativa.

É nesse sentido que realizamos a analogia ao trabalho inacabado de Sísifo - pensando como esta simbologia nas contradições cotidianas contemporâneas e nas formas de resistência às violações permanentes, nos permite ler essa sociabilidade como a que nos submete a estado de exceção permanente a despeito de sua base discursiva dos direitos e de aparentes "avanços formais". Inspiramo-nos em especial na leitura de Albert Camus (1942) sobre o mito, em clara reflexão sobre a dimensão do absurdo na modernidade.

Para tanto é preciso entender no contexto nacional marcas de nossa constituição histórica, as quais deságuam em clara formulação de uma redemocratização incompleta nos anos de 1980. Considerando nossa Constituição Federal (1988) como fruto de pacto conservador e com, para aquele momento histórico, característica "híbrida e ambígua" (FERNANDES, 1989) - talvez o único formato compatível com o sentido do Brasil como país da periferia do capitalismo - procuramos compreender a forma como essa dinâmica de extração do valor direciona os investimentos estatais a partir dos anos 2000 no campo das políticas urbanas, em especial tratando-se de recursos para saneamento e habitação.

Construímos na nossa argumentação o que percebemos como uma relação instrumental e periférica com os direitos, cujo arcabouço jurídico que poderia orientar tais investimentos no que se acreditava constituir parte dos instrumentos que expressam o "direito à cidade" (LEFÉBVRE, 2008), como o Estatuto das Cidades (Lei 10.257/2001) e a regulamentação do Fundo Nacional de

\footnotetext{
${ }^{2}$ Nossa leitura orienta-se pela compreensão que o valor não é uma categoria econômica. Jappe (2103) expõe o quanto se trata, conforme expõe Marx, em algo que é determinado pelo trabalho abstrato e acaba por "subordinar a vida dos indivíduos e da humanidade inteira aos mecanismos dessa acumulação, sem nem mesmo disso ter consciência" (p.140), como uma característica clara do fetichismo da mercadoria. É apenas na sociedade capitalista que ocorre essa autonomização do valor e, portanto, da razão econômica (p.141).
} 
Habitação de Interesse Social (FNHIS Lei 11.124/2005, regulamentada em 2006), datam dessa década.

Entendemos que muitas das formas/causas das lutas sociais e de debates em torno dos direitos como elementos específicos reativos às violações encerram-se na centralidade formal e abstrata do ser humano nessa sociabilidade. Nos seus marcos normativos, expressam formas como se consolidam as conquistas em contradições e disputas sobre concepções distintas dessa sociabilidade. Quando dessa forma, ao se constituírem como "ajustes" numa dinâmica intrínseca e perenemente desigual e opressora, trazem inviabilidades e obsolescências já no processo em que se configuram e no momento em que aparecem como conquistas. Disputados dentro da ordem e aprisionados ao cabo por sua dinâmica, acabam sistematicamente por se voltarem para um grau de acesso à pequena parte da riqueza socialmente produzida - seja através do usufruto de bens e serviços, seja a partir de regulações normativas mediadoras formais das violações existentes.

O trabalho divide-se em três momentos. Um primeiro voltado à problematização dos alicerces na nossa conformação do atual contexto de financeirização e sua especificidade neste país periférico na relação com a extração do valor no período pós anos 2000. Particularmente quando ascende ao governo federal uma coalização de centro-esquerda de pactuação populista e compromissada com a compatibilização entre medidas de ajuste neoliberais e garantia do crescimento econômico / desenvolvimento e melhoria residual de indicadores sociais. Partimos então para uma breve contextualização sobre o lugar e o sentido de investimentos e mediações realizadas a partir do Estado capitalista nos setores de políticas de saneamento e de habitação, situadas como de "desenvolvimento urbano", entendendo o sentido específico do "urbano" para o desenvolvimento capitalista na contemporaneidade.

Por fim, mas sem nenhuma intenção de buscar considerações conclusivas ou projeções de saídas, problematizamos o atual momento que vivenciamos, tendo como eixo central o que claramente identificamos, em tempos presentes e com base na dinâmica de acumulação e de produção das cidades, como uma abstração se pensado nos limites dessa forma social: o "direito à cidade". 


\section{DESENVOLVIMENTO CAPITALISTA E ESPECULAÇÃO NA PERIFERIA: CONVERGÊNCIAS ENTRE DESTRUIÇÃO E PROGRESSO EM TEMPOS DE FINANCEIRIZAÇÃO}

Nossa pretensão central é problematizar o curso de aparente dissociação entre direitos construídos na dinâmica histórica e normativamente assumidos e o seu enquadramento na concretude do movimento de acumulação capitalista. Essa combinação dissonante impulsionada pela submissão à financeirização impõe estágio avançado de aprofundamento das contradições dessa sociabilidade em especial se pensarmos o caso da produção do "urbano" no Brasil.

Aparente, partimos da leitura que problematiza o quanto essa dissociação já se encontra como elemento originário dessa ordem social. Reconhecemos que assumem formas particulares em cada tempo histórico e território / dinâmica societários, possuindo clara funcionalidade para o movimento incessante de busca do valor.

Essa dinâmica acirra suas contradições insolúveis em tempos de diluição das possibilidades produtivas de crescimento do capital, em especial a partir da globalização financeira dos anos de 1970 em diante, quando se identifica aí o que Brunhoff (2010) ainda reconhecia como "uma das fases do capitalismo nas quais a finança assumiria provisoriamente o posto de comando da economia" (p.33), de forma semelhante ao que ocorre no final do século XIX até 1914. Porém, a partir dos anos de 1980, com ampla política de liberalização financeira internacionalizada, parece que práticas e instituições financeiras tão antigas do capitalismo, como crédito bancário, mercados de títulos, seguros, câmbios de moedas nacionais assumem uma dinâmica própria em relação a sua função "normal" de financiamento do comércio e das atividades produtivas reais (BRUNHOFF, 2010, p.34).

Esse "descolamento", como movimento próprio do capital na sua busca por valorização em contexto de agravamento das condições produtivas, "aparece" como uma fase em diferentes momentos da História de desenvolvimento do capitalismo.

Em final do século XX e na sua passagem para o XXI consolida a universalização de uma forma social na qual todas as relações são efetivamente reificadas e mediadas a partir de relações mercantis. O caminho do "desenvolvimento" e sua própria condição paradoxal refletem-se em um processo que conduz ao colapso: não pela contraposição das forças produtivas ou mesmo pelo limite lógico do capital de submissão do trabalho vivo (MENEGAT, 2012), mas pela própria intensificação de seu poder endógeno de destruição. 
Tal cenário desenha-se como quadro no qual questões como a vida sobre a terra e as mediações civilizatórias realizadas pelos "direitos" - estes, limitados aos pactos formais e submetidos na sua exequibilidade aos caprichos da dinâmica mercantil - tornam-se cada vez algo mais periférico e residual, perdendo sua funcionalidade até no seu caráter de reprodução das condições necessárias ao valor.

É nesse sentido que Chesnais (2010) nos lembra do grau de autonomização do capital no curso de sua dinâmica, especialmente no que tange à ideia de "capital em geral" apresentada nos Gründrisse por Marx (2011). O autor expõe que

Fortalecido pela liberdade de movimento que ele recuperou em escala planetária e submetido às exigências da rentabilidade pela nova forma de acionista nascida dos fundos de pensão e de aplicação financeira (os mutual founds), o capital afirma hoje, a um grau jamais atingido antes, os atributos que o fazem um 'valor em processo', uma força impessoal voltada exclusivamente para sua autovalorização (CHESNAIS, 2010,p.98).

Essa concepção da força impessoal não se constitui em uma característica especifica de tempos de financeirização, conforme podemos ver em Marx já na leitura do grau de desenvolvimento do capitalismo no século XIX. Consiste, sim, na própria forma fetichizada da formação social burguesa, na qual as mediações decorrem de relações submetidas ao autômato da busca incansável do valor.

Entendemos que o valor, com base na leitura de Kurz (1998) sobre a crítica marxiana, não é sobremaneira concebido como algo positivo, mas como possuidor de uma existência autosuficiente como aparência nessa sociabilidade. Para ele "o 'valor' já contém em sua forma essencial (descrita no primeiro capitulo de O Capital) uma contradição insolúvel que conduz, inexoravelmente, ainda que isso leve muito tempo, à sua crise final" (p.9). É assim que no movimento de constituição do capital como ordem sistêmica e integradora (à fórcepes e impingindo integração subalterna) dos países periféricos aos centrais sob forma de Estado Nação, marcam a instituição de uma "época moderna". Tais características das "origens da modernidade e do capitalismo, remontam à Renascença e à Reforma Protestante" datando, no nosso entendimento, de final do século XV (LÖWY \& SAYRE, 2015, p.40) 3 .

\footnotetext{
33 Partilhamos da leitura de Kurz (1998) sobre compreensões distintas quanto ao nascimento da "era moderna". Na nossa compreensão, percebemos a origem dessa "era" como algo que advém de movimentos, praticas e ideias ainda com o Renascimento e as reformas protestantes (entre os séculos XV e XVI), alimentado pelos ideais iluministas do século XVIII. De todo modo, Kurz sinaliza que "consideram-se razões proeminentes para a ascensão da modernidade, tanto as inovações artísticas e científicas do Renascimento
} 
A forma, mutante em cada tempo histórico, porém permanentemente periférica de como se integra o Brasil nesse processo, após farto uso e abuso de sua condição de colônia escravista extrativista funcional à acumulação primitiva, nos auxilia bastante a entender nossos paradigmas positivos sobre o direito normativo, a crença no Estado de direito e as leis que regulam as políticas públicas a despeito do explícito movimento destrutivo do Capital. Isso tudo para pensarmos uma abordagem que não considere haver necessidade de "ajustes" nas políticas públicas ou afirmação do Estado de direito, na medida em que não consideramos que a questão central foca-se em serem ambos mais ou menos eficazes. Esse mote é impulsionado ao se olhar sua aparente condição de des-sintonia e mesmo de "absurdo" em relação aos fatos da realidade, parecendo que, a despeito dos registros jurídico-normativos, das pactuações institucionais e internacionais, da institucionalidade construída no Ocidente em torno dos direitos, a pedra role montanha abaixo, parecendo fazer tudo ser iniciado do zero.

Encontramos vastas reflexões críticas que recuperam na História como se constitui a ideia de Estado de direito e sua vocação contratualista hobbesiana para a repressão como forma de assegurar a sensação coletiva de ordem social e as possibilidades institucionais da ideia de progresso ${ }^{4}$. Essa conformação do Estado Moderno se alicerça - também como é sabido - sobre os pressupostos racionais jurídico-formais da noção de direitos, tendo como pilar os de dimensão individual, civis, os quais anunciam o respeito à propriedade privada como expressão máxima e conquista dignificante dos esforços laborativos dos indivíduos, na medida em que para ele o trabalho estabelece em tudo a diferença do valor (LOCKE, s/d, p.46).

Pautado nessa premissa de garantia, cabe ao Estado não intervir em tais liberdades, mas garantir as condições de seu exercício em um determinado padrão civilizatório, à recepção de seus frutos aos que se empenharam e possuem capacidades, a partir das disputas concorrenciais que levam à autoregulação e ao funcionamento sociais conduzindo, naturalmente, ao progresso.

Portanto, na constituição dessa sociabilidade, a partir de um determinado caldo de cultura e de práticas sociais as quais possuem por centralidade a ética do trabalho como elemento

Italiano quanto as grandes viagens de descobrimento desde Colombo, a ideia protestante e calvinista da responsabilidade específica do individuo, a libertação iluminista das crenças irracionais e o surgimento da democracia moderna na França e nos Estados Unidos" (p.239).

4 Nisbert (1996) recupera como se constrói a ideia de progresso no ocidente, pensando seu sentido na Antiguidade e as transformações e a centralidade desta nos tempos modernos. Para esse autor, a ideia de progresso se espraia entre 1750 e 1900 tanto popularmente quanto nos círculos intelectuais e filosóficos. É uma das ideias importantes para a civilização ocidental. O autor atribui à ideia de progresso o fato das pessoas acreditarem que ideias relevantes como as de liberdade, igualdade e soberania passem a ser objetivos possíveis de se lograr na terra, não apenas como promessa divina (p. 243). 
dignificante e que conduz o ser humano ao estatuto de "indivíduo possessivo" (autor), a mediação necessária de instrumentos jurídicos normativos em sua clara acepção coercitiva é algo que remonta aos primórdios da modernidade. Porém, a forma social que se consolida a partir do século XIX advém de possibilidades efetivas que combinam a regulação visando à ordem e à estabilidade institucional - para tanto, concede-se alguma partilha da riqueza socialmente produzida para se assegurar a reprodução de tais relações fetichizadas sob o véu da reprodução da vida.

As políticas públicas, entendidas como uma dessas expressões de mediação das contradições sociais, dentro da perspectiva de reprodução das condições de acumulação, vivenciam a reestruturação e reconfiguração das formas de acumulação em contexto de crise estrutural do capital. Na nossa leitura, com o acirramento da crise do Capital como sociabilidade, distanciam-se do que aparecia como caráter contraditório quando se generalizam, na Europa, no auge do ciclo expansionista do século XX. Assumem, em especial na periferia do capitalismo (e para a periferia, na medida em que possuem formatos claramente financiados pelos países centrais), caráter criminalizador, coercitivo e punitivo, acirrando a face do que se intitula como "Estado penal" como clara técnica de "invisibilização dos 'problemas sociais'. Como exemplo, basta mirar as políticas de segurança tanto em países centrais como periféricos - as quais tem como horizonte o extermínio ou o encarceramento de pobres e de grupos étnicos específicos, considerando ser a prisão "a lata de lixo judiciária em que são lançados os dejetos humanos da sociedade de mercado" (WACQUANT, 2013, p.21) .

Destarte, embora seja a realidade dinâmica e contraditória e, portanto, inapreensível no seu tempo, em relação às ações estatais reforçamos que se perde ostensiva e ofensivamente possibilidades de compreensão destas como contraditórias, na medida em que crescentemente priorizam do estrategicamente ${ }^{6}$ o ordenamento do espaço e do tempo de circulação do capital no território. Não nos referimos à disputa dual entre os que possuem os meios de produção e se

\footnotetext{
${ }^{5}$ Wacquant (2013) trabalha dimensões / estratégias importantes das sociedades contemporâneas a partir dos Estados para tratar condutas ameaçadoras. Socializa-se aqueles que "sujam" ambientes da paisagem urbana, integrando-os em alguma medida em alojamentos ou através de ações assistenciais que provenham alguma renda. A segunda é a medicalização, buscando o tratamento medicamentoso aos adictos que vivem nas ruas, tratando como patologia individual. Por fim, o pesado investimento em penalização, na medida em que o "nômade urbano é etiquetado como delinquente (...) e tratado como tal; ele deixa de integrar o contingente dos 'sem teto' quando é colocado atrás das grades. A 'construção legal do sem teto' quase como não humano condensa seus direitos, o reduz efetivamente a um não cidadão e facilita o processo criminal" (pp.20-21)

${ }^{6}$ O. Arantes (2012) nos avisa o quanto "é bom não perder de vista a origem militar da palavra estratégia, que da esfera semântica da guerra econômica foi transplantada, com involuntária precisão, para um urbanismo que pelo menos confessa precisar de adversários, aliás facilmente identificáveis" (p.36)
} 
apropriam da maior parte da riqueza socialmente produzida, e as disputas por maior acesso a estas por parte dos que vendem sua força de trabalho. O que se problematiza aqui é que essa dinâmica de produção do valor, de "metabolismo predatório" (MÉSZAROS, 2007) do capital, de movimentos permanentes de destruição, construção, de assento de sua forma de crescimento sobre indústrias predatórias como a bélica ${ }^{7}$, não possui sentido racional, se depreende de qualquer teleologia constituída como matriz racionalista explicativa da modernidade. Ainda, os elementos que parecem contraditórios - na medida em que a realidade o é -, adquirem centralidade e a funcionalidade sob a ótica de esforços no sentido de obtenção do valor em contexto de crise, que cada vez, têm sido mais explicitadas.

Portanto, cabe aqui a relação entre essa dinâmica de financeirização e sua relação com o sentido que o urbano assume a partir dos anos de 1990, em especial no Brasil. Se, na sua origem, o urbano-industrial era uma forma social específica do capitalismo (LEFÉBVRE, 2008), impondo dinâmica dissociada e subordinada da urbanização à industrialização voltada para a garantia das condições de produção, essa realidade vai, aos poucos e de modo bastante heterogêneo, se modificando ao longo do século XX.

Chegamos ao seu final, ao que Arrighi (1996) intitula como o "longo século XX", lembrando-nos como, de forma distinta dos sistemas monetários mundiais anteriores, nos quais as altas finanças eram controladas por banqueiros e financistas privados visando o lucro, a partir do sistema criado em Breton Woods,

A produção do dinheiro mundial foi assumida por uma rede de organizações governamentais, primordialmente movidas por considerações de bem estar, segurança e poder - em princípio, o FMI, o Banco Mundial e, na prática, o Sistema da Reserva Federal dos Estados Unidos, agindo em concerto com os bancos centrais dos aliados mais íntimos e importantes do país. Assim, o dinheiro tornou-se um subproduto das atividades da gestão do Estado (p.287).

É sob essa centralidade e sentido do dinheiro no século $X X$, que se acirra o caminho do "desenvolvimento cego" construído por um século (POLANYI, 2000) ${ }^{8}$, chegando-se a um cenário de

\footnotetext{
${ }^{7}$ A indústria bélica como forma mais explícita e banal de relação entre crescimento econômico e destruição - lembrando o ciclo de ascensão da produção do valor alcunhado como "anos de ouro" o qual comprimia duas grandes guerras mundiais e diversos conflitos bélicos espalhados pelo mundo. Essa relação de progresso destrutivo do que se intitula como humanidade pode ser mapeada em todas as esferas da vida, como, por exemplo, no consumo ampliado de venenos herbicidas através dos alimentos, na lógica predominante da industria farmacêutica, nas políticas de extermínio de jovens negros pobres em regiões periféricas pelas políticas de segurança pública, nos previsíveis, mas catastróficos desastres ambientais, etc) ${ }^{8} \mathrm{Na}$ linha do se refletir sobre a expressão do absurdo na vida moderna, citamos a reflexão do autor sobre a civilização do século XIX. Para ele, esta "não foi destruída por ataques de bárbaros externos ou internos; sua vitalidade não foi solapada pelas devastações da Primeira Guerra Mundial, nem pela revolta do proletariado
} 
desindustrialização, de precarização crescente das relações de trabalho, de devastação de recursos naturais a partir de sua exploração maquinizada e predatória, com incremento de população sobrante nos centros urbanos e com situações de colapsos, contrapondo-se às ideias lineares de progresso e à leitura de mercado auto-regulador tratada por Polanyi (2000) ainda na primeira parte desse século como "perfeita utopia" - questões centrais para o "padrão civilizatório burguês".

A isso se atribuiu pesadamente na segunda metade do século $X X$ a necessidade de reformulações no campo do planejamento urbano e, também regulatório, tratando das cidades como lugares que deveriam se submeter a uma adequação estratégica para que se tornassem competitivas e produtivas, vendáveis, capazes de concorrer entre si à atração de investimentos (VAINER, 2012), assumindo a lógica do empresariamento do urbano, em espaços que não cabem abrigar o "ambiente de pobreza" 9 .

Tais movimentos não ocorreram apenas pelo limite das transformações oriundas dos "avanços" técnico científicos e consequentes reestruturações produtivas, dada a obsolescência crescente do trabalho vivo em determinados postos. Advieram, especialmente, da necessidade de prevalência da dimensão especulativa sobre a terra, da retomada dos territórios centrais como espaços infraestruturados "esquecidos"10 (já como forma de "estoque de terra") e revalorizados sob a intervenção pesada do Estado como agente das corporações em processos explícitos de gentrificação.

A ação de remoções de populações originárias empobrecidas e destituídas da integração pelo trabalho formal na realização de "reformas urbanas" para "revitalização"11 das áreas que passam a ser resignificadas pelos interesses mercantis e especulativos é elemento comum que

socialista ou de uma classe média baixa fascista. Seu fracasso não foi consequência de alguma suposta lei de economia, como a taxa de lucros decrescentes, a do subconsumo ou a da superprodução. Ela se desintegrou como resultado de um conjunto de causas inteiramente diferentes: as medidas que a sociedade adotou para não ser aniquilada, por sua vez, pela ação do mercado autorregulável" (p.289).

${ }^{9}$ Vainer (2012) chama a atenção para o quanto essa "transformação da cidade em mercadoria (de luxo) repercute no olhar lançado sobre a pobreza" (p.82). A transformação da pobreza em ambiente é um dos elementos dos planejamentos estratégicos (ou neoplanejadores urbanos, para o autor), na medida em que esse modelo de planejamento de inspiração das escolas norteamericanas de negócios ao equalizarem as cidades às mesmas condições das empresas, aonde se necessita pensar soluções para aguçar possibilidades de produzir crescente competição entre os territórios.

10 Para Otília Arantes (2012), Neil Smith denuncia, na realidade especifica dos Estados Unidos, a noção de cidade revanchista na "retomada agressiva das gentrificações depois das grandes falências do fim dos anos de 1980, mas sobretudo como reação à deterioração urbana provocada pela primeira onda de desregulações e cortes dos programa sociais" (p.37).

11 O. Arantes (2012) problematiza o uso positivador dos termos como formas eufemísticas - como "renovação urbana", "reforma urbana", entre outros - de processos de gentrificação. 
associa intervenções estatais em países tão distintos quanto os do centro e da periferia do capitalismo. Para O. Arantes (2012),

A gentrificação é uma resposta específica da maquina urbana de crescimento a uma conjuntura histórica marcada pela desindustrialização e consequente desinvestimento de áreas urbanas significativas, a terceirização crescente das cidades, a precarização da força de trabalho remanescente e sobretudo a presença desestabilizadora de uma underclass fora do mercado (p.31).

Portanto, o que está exposto é o caráter absurdo e mesmo estéril que assumem as premissas que fundam esse padrão civilizatório e que orientam, ao menos no plano da justificativa ideopolítica, as manifestações estatais e desenhos de regulações e de políticas públicas. Associamos, como livre pensar, essa contextualização rápida e superficial ao que Camus (s/d), ainda na metade do século XX (1942) e em contexto imediatamente posterior a duas grandes guerras mundiais, assinala como a tomada de consciência da absurdidade dos tempos.

\section{O ESTATUTO DAS CIDADES E O SENTIDO DOS INVESTIMENTOS PÚBLICOS EM SANEAMENTO E HABITAÇÃO A PARTIR DOS ANOS 2000}

É sob a chave do absurdo, mas entendendo sua funcionalidade quando enxergamos o movimento histórico pela busca de extração de valor, que problematizamos o que aparece como dissociação entre marcos regulatórios de saneamento e de habitação, lendo sua materialização a partir de ações objetivas do Estado, associado às grandes corporações protagonistas nos setores.

Vimos como a lógica predatória da financeirização, em processo histórico no qual se consolida o descolamento entre dinheiro e valor e o movimento incessante de busca dessa valorização, capitaneada pela gestão estatal em nome de interesses corporativos, marca fortemente os rumos da nossa "civilização". Sendo o dinheiro um subproduto dessas formas de gestão estatal em tempos atuais, ousamos dizer que os esforços de gestão pública, quando muito, se voltam para a amenização dos impactos dos colapsos, ou, nas palavras de Menegat, para uma "gestão da barbárie".

No Brasil dos anos de 1990, após duas décadas de ditadura as dificuldades para construção do processo constituinte e a tentativa de reorganização da sociedade brasileira sob preceitos "republicanos democráticos", em processo que Fernandes (1989) denuncia como uma "pactuação conservadora", ocorre a agudização da crise (terminal) do capital dos anos de 1970, com características que mencionamos anteriormente.

As marcas deixadas pelo ciclo de expansão, quando o Estado desenvolvimentista autoritário investe de forma empresarial e concentrada na ampliação da urbanização de forma 
desigual inter-regional e regiões e intrametropolitana no Brasil, acentuam as desigualdades oriundas de nossa formação social.

Após os limites expansionistas e das contradições do regime autoritário, com ações voltadas para a integração nacional de forma periférica no capitalismo mundial e, internamente, para a construção de legitimidade da ditadura, assistimos ao recrudescimento da crise nos anos de 1990, quando se iniciam medidas ainda tímidas (frente a um Estado dilapidado pelos direcionamentos nacional-desenvolvimentistas da ditadura militar) de adoção de reformas neoliberais. Uma das expressões dessa crise, é o colapso do Sistema Financeiro de Habitação (SFH), que financiava, através do Banco Nacional de Habitação $(B N H)^{12}$, investimentos em saneamento e em habitação para determinados públicos ${ }^{13}$ e fins. Cabe ressaltar o quanto o saneamento, no Brasil, sempre foi considerado um serviço urbano (COSTA E RIBEIRO, 2013) e a falência das estruturas que financiavam o modelo implementado pelo Plano Nacional de Saneamento PLANASA (1971-1986) na ditadura no contexto de acirramento do colapso capitalista na produção de valor nos anos de 1980, acabaram por estagnar e mesmo regredir quaisquer formas de investimento produtivo nessas políticas públicas entre final dos anos de 1980 e início dos anos 2000.

A aprovação do Estatuto das Cidades (Lei 10.257/2001) ocorre nesse contexto, da inviabilidade das condições de financiamento e de produção de valor a partir da relação urbanização-industrialização. Tal fato, somado aos embates e negociações em torno das formas de descentralização dos parcos recursos para investimentos públicos, impuseram ua regulamentação dos capítulos referentes à política urbana da Constituição Federal bastante instrumental às disputas por recursos existentes. Após mais de uma década depois da promulgação da Constituição

\footnotetext{
12 O Banco Nacional de Habitação (BNH), criado no início da ditadura militar brasileira (1964), passa a contar, para o fomento dos projetos de urbanização, com recursos do Fundo de Garantia por Tempo de Serviço (FGTS) a partir de 1966. Concentrando o planjamento e os investimentos, o BNH "instituiu um modelo nacional de oferta de serviços urbanos assentado, de um lado, sobre uma agencia federal que centralizava a formulação e o financiamento das políticas e, de outro lado, sobre agencias locais (estaduais ou municipais), encarregadas de sua implementação" (ARRETCHE, 2000, p.76). Além dos problemas de articulação institucional, da orientação de financiamento desigual no território e em relação ao público alvo, o modelo de financiamento pelo FGTS entra em crise junto com o colapso do capital nos anos de 1980.

${ }^{13}$ Oliveira (2013) demonstra através de dados econômicos como não houve, no período pós-1964, nenhuma redistribuição de renda para baixo, nem para os extratos médios, tampouco para os baixos. Há algum incremento da renda das camadas médias a partir do que ele identifica como "requerimentos técnicoinstitucionais da matriz da nova estrutura industrial e, portanto, das ocupações médias que essa matriz cria: é uma 'necessidade' da estrutura produtiva em seu sentido global e não um 'estado de bem estar' das classes médias" (pp.98-99), ainda que essa política econômica tenha beneficiado, colateralmente, as camadas médias no acesso a bens duráveis, como habitação e justificado a estrutura de um sistema financeiro para o setor contemplando aqueles com mais de 5 (cinco) salários mínimos de renda.
} 
Federal (CF 1988), os mecanismos jurídicos aprovados expressam o curso da realidade nas formas pragmáticas e capitalistas de descentralização político administrativa.

Conforme Arretche (2000), o mito que descentralizar democratizaria na perspectiva do controle social, da universalização e de uma eficiência e eficácia na gestão dos serviços, ficou exposto como fratura. Nos anos 2000, não à toa, são regulamentadas medidas que explicitam os caminhos da "universalização" que garantissem as parcerias público-privadas e os mecanismos voltados para alguma rentabilidade para o capital em sua crise profunda.

No entanto, ressaltamos que, desde a sua formulação a partir da pressão de movimentos sociais ligados às lutas pela chamada reforma urbana, um embróglio em torno da formação da cidade capitalista já ocorria. Existia profunda crença na articulação de instrumentos jurídicos do que deveria, na sua elaboração inicial, expressar a resignificação sobre a forma de ocupação do território urbano, orientando-se pela "função social da cidade e da propriedade", expressa, dentro do desenho dessa ordem social, uma utopia de compatibilização do direito de propriedade com o uso público do espaço e de serviços urbanos ${ }^{14}$.

Não à toa, nos anos que se seguem formalizam-se práticas já instituídas as quais viabilizam normativamente os mecanismos de prevalência do acesso à cidade para consumidores, dentro da lógica do valor. Já em 2004, nos marcos da contrarreforma do Estado, é promulgada a lei federal no 11.079/2004 a que institui as parcerias público-privadas, assegurando os mecanismos necessários para implantação dos serviços como mercadoria em diferentes nichos de mercado. Nesse esteio, a lei que assegura consórcios intermunicipais (Lei Federal no 11.107/2005), acaba por servir para a formação de cartéis regionais para prestação de serviços aonde não há grandes disputas por lucratividade ${ }^{15}$.

A despeito das formas de resistências em ocupações, seguem regulamentações que expressam esforços (estratégias?) jurídicos (as) quanto à formalização legal da regularização fundiária, priorizando a propriedade individual. Nesse contexto, o empresariamento das cidades ${ }^{16} \mathrm{e}$

\footnotetext{
${ }^{14}$ Uma boa reflexão sobre a utopia da reforma urbana e seu ocaso é possível ser lida em COSTA (2012). A autora nos expõe como a questão central do ocaso da reforma urbana não se assenta sobre problemas de eficácia de políticas públicas, ou de conflitos no campo político sobre o sentido da reforma urbana, mas na sua própria crença como mecanismo de transformação social nessa ordem.

15 Heller; Bastos et all (2013) demonstram como a definição legal da Lei sobre saneamento, embora aponte para um "modelo ideal" de prestação de serviços, acaba por permitir comportar diferentes lógicas organizacionais, "podendo implicar maior ou menor propensão a se aproximar da idealização formulada" (p.483)

16 Vainer (s/d) demonstra como a questão do empresariamento das cidades têm início ainda nos anos de 1990 como uma estratégia neoliberal de planejamento, visando tornar as cidades competitivas e flexíveis. $\mathrm{Na}$
} 
o incremento de suas capacidades de atratividade de capital, a regulamentação acompanha a viabilização de ações em curso. Em tempos de aprofundamento das ações especulativas, a regulação é elemento apropriado pela dinâmica financeira como forma de garantir algum grau de segurança jurídica dos investimentos, associado à remuneração prévia das altas taxas de juros. Entre várias ações legislativas, citamos algumas emblemáticas, pois incidem sobre regularização, propriedade fundiária e investimentos em serviços. Leis federais como a 10.931/2004 asseguraram a gratuidade do registro imobiliário nos programas de regularização e a de no 11.481/2007 visou facilitar os processos de regularização fundiária pelos municípios nos assentamentos informais consolidados em terras da União.

Nesse movimento e a partir da grande manifestação do colapso especulativo a partir da quebra hipotecária nos EUA ${ }^{17}$ - rebatendo em todo o mundo -, é lançado o Programa Minha Casa Minha Vida (PMCV, Brasil, 2009). Financiado dentro de política pública mais ampla de cunho desenvolvimentista, em contexto de acirramento da crise capitalista, o Programa de Aceleração do Crescimento (PAC), ainda no início do segundo governo de Luis Inacio Lula da Silva (2003-2010), constitui-se em parceria direta entre o Estado e o mercado imobiliário - este, força motora do processo (ARANTES e FIX, 2009) - para a construção de moradias de $32 \mathrm{~m}^{2}$ para famílias entre 0 a 10 salários mínimos - com forte concentração de investimentos dentro desse universo orientado para o que efetivamente interessa ao mercado imobiliário ${ }^{18}$.

reflexão específica, aborda o caso da capital do Rio de Janeiro e sua remodelação, desde as gestões do Prefeito Cesar Maia (1993-1996, 2001-2004, 2005-2008), nos anos de 1990 a 2000, passando por Eduardo Conde (1997-2000), à preparação para a realização dos Megaeventos, sob a batuta de Eduardo Paes (2009 à atualidade).

17 Fix (2011), em interessante trabalho, demonstra o forte laço entre circuito financeiro e mercado imobiliário nos EUA na explosão da crise em 2007. Para ela "A crise financeira mundial evidenciou o alcance dos vínculos entre o imobiliário e o financeiro que, em diversos países, intensificaram-se a partir dos anos 1980. O crescimento dos empréstimos de tipo subprime - considerados estopim da crise atual - fez parte do salto ocorrido na massa de capital fictício nesse período. Entre 1980 e 2010, o valor dos ativos financeiros mundiais - ações, debêntures, títulos de dívida públicos e privados, e aplicações bancárias - cresceu 16,2 vezes enquanto o PIB mundial aumentou pouco menos do que 5 vezes no mesmo período" (p.2). No entanto, a autora salienta que o circuito imobiliário não segue necessariamente o movimento geral das transformações econômicas e sociais, exigindo um esforço especifico de compreensão, especialmente se pensarmos as particularidades brasileiras da formação do mercado imobiliário, bem distintas da norte americana. O que importa, no entanto, são as formas de apropriação dessas dinâmicas para produção de valor em cada lugar, assim como os seus rebatimentos.

${ }^{18}$ Arantes e Fix (2009) demonstram como "o perfil de atendimento previsto pelo pacote revela, por sua vez, o enorme poder do setor imobiliário, pois favorece claramente uma faixa estreita da demanda que mais the interessa (...). 0 déficit habitacional urbano de famílias entre 3 e 10 salários mínimos corresponde a apenas $15,2 \%$ do total (dados da Fundação João Pinheiro para o ano 2000), mas receberá $60 \%$ das unidades e $53 \%$ do subsídio público" (p.3). 
A Lei Federal № 11.977/2009 é aprovada para regulamentar o Programa Habitacional, que adquire "ares" de política pública, sob pretexto de viabilizar a regularização fundiária de assentamos informais e permitir acesso ao sonho da casa própria à população que possui renda entre 0 e 10 salários mínimos, perfil histórico de concentração do déficit habitacional brasileiro.

Um dos elementos importantes na construção do Estatuto das Cidades (Brasil, 2001) foi a tentativa de integrar o que se dissociou nessa ordem burguesa/positiva: a leitura sobre moradia, como direito e bem que integra condições de adequação ${ }^{19}$ e de habitabilidade no território. Porém, no movimento incessante de apropriação de todas as esferas da vida e, reconhecendo na aposta dos movimentos que lutam pelo direito à cidade a assunção dos aspectos jurídico-legais, a dinâmica capitalista associa mecanismos explícitos e violentos de expulsão / remoção, a outros não menos violentos, mas socialmente menos visíveis e ideologicamente camuflados sob a racionalidade legal.

Desde então, três têm sido esses caminhos do "consenso": remoções sob a justificativa do risco, tanto social quanto ambiental e, por fim, a negociação direta com moradores tanto pelo Estado quanto por empresas privadas, para compra de imóveis a partir da garantia do direito de propriedade individual $^{20}$.

Nos primeiros casos, em situações com ou sem desastres, a prática corriqueira de indenização, de pagamento de aluguel social ou mesmo de alocação em programa habitacional do Minha Casa Minha Vida (2009) acontece na maioria das vezes com a remoção da população para lugares distantes de sua área de origem, rompendo laços de vizinhança, entre outros.

Essas "ofertas" ocorrem, em geral, à famílias em residências localizadas em áreas para especulação, gerando a inviabilidade de permanência das mesmas nos seus locais de origem. A mercantilização de todas as esferas da vida se faz pela necessária quebra de possibilidades de projetos coletivos de resistência, ocorrendo pressões das formas mais perversas possíveis.

\footnotetext{
${ }^{19}$ A noção de déficit habitacional, no campo da produção de indicadores oficiais, conforme a Fundação João Pinheiro (FJP, 2013), realiza a contagem a partir da consideração de quatro elementos: "(i) domicílios precários; (b) coabitação familiar; (c) ônus excessivo com aluguel urbano; e (d) adensamento excessivo de domicílios alugados. Os componentes são calculados de forma sequencial, em que a verificação de um critério está condicionada à não ocorrência dos critérios anteriores" (p.5). Segundo resultados preliminares para 2013, a Fundação calculou o montante de 5,846 milhão de unidades faltantes, com maior concentração do déficit nas regiões do Sudeste e Nordeste. $O$ elemento que mais incide para a conformação do déficit tem sido o excessivo valor gasto com aluguel.

${ }^{20}$ Tem sido recorrente também, desde os investimentos do Programa Favela Bairro, ainda em tempos de gestão de Cesar Maia, no Rio de Janeiro, por exemplo, uma outra forma de expulsão a posteriori à "entrada" dos investimentos: a "integração" à rede formal de serviços, com as melhorias urbanas, criam dificuldades objetivas de sustentabilidade naquela nova realidade, na qual se passa a arcar com serviços urbanos caros e com burocracia que dificulta o acesso a tarifas sociais e aos requisitos da "cidade formal".
} 
No plano do saneamento, a formulação da Lei das Diretrizes Nacionais para o Saneamento Básico (11.445/2007, Brasil, 2007) como a narrativa de princípios universalistas, democratizantes e de acessibilidade ${ }^{21}$, não têm conseguido, obviamente, frear a produção e a distribuição desigual e mercantil de serviços fundamentais à vida e mesmo às condições sanitárias, como a provisão de água potável e o tratamento e despejo adequado de esgoto.

Afunilando os rumos dos investimentos pautados pelos objetivos especulativos sobre o território, as medidas de ajuste fiscal, como mecanismo de resposta à queda da taxa de juros, passam a ser a tônica não apenas para os governos brasileiros, mas latinoamericanos. Caracterizam-se em contingenciamento quando se trata de recursos para ampliação de serviços e no redirecionamento dos recursos existentes para lastrear as dívidas públicas internas e externas do país ou para incremento de ganhos no mercado financeiro, assegurando o estofo necessário à atratividade de investimentos.

Se o circuito de serviços, na leitura tradicional da crítica à economia política, é destituído da capacidade de produção de valor, na medida em que não engendram trabalho produtivo e configuram como investimentos na órbita de reprodução da força de trabalho, o cenário de reconfiguração do "mundo do trabalho" com crescente terciarização das economias, os deslocamentos da capacidade de produção de valor e o próprio sentido do trabalho no capitalismo, têm impresso à essa esfera das relações sociais características bastante peculiares. Na medida em que várias das empresas que implementam esses serviços, a despeito da qualidade objetiva da prestação dos mesmos e dos produtos ofertados, possuem ativos no mercado financeiro e partilham lucros obtidos entre seus acionistas, justificando o redirecionamento de recursos existentes para alimentar a ciranda especulativa ${ }^{22}$.

\footnotetext{
${ }^{21} \mathrm{~A}$ lei anuncia princípios como: (i) a universalização do acesso; (ii) a integralidade dos diversos serviços de saneamento básico; (iii) a prestação de serviços de abastecimento de água, de esgotamento sanitário, de limpeza urbana e manejo dos resíduos sólidos realizados de forma adequadas à saúde pública e à proteção do meio ambiente; (iv) e a disponibilidade, em todas as áreas urbanas, de serviços de drenagem e de manejo de águas pluviais adequados à saúde pública e à segurança da vida e do patrimônio público e privado (HELLER et all, 2013).

22 Um caso que ilustra tal fato são os investimentos não realizados pela SABESP nos anos de 2013 e 2014 no Sistema da Cantareira (SP) para captação, adução, reserva e distribuição de água no estado de São Paulo, quando seu conselho realiza a opção pelo não investimento e distribuição de seus lucros entre seus acionistas. O serviço de acesso à água entrava em colapso no estado de São Paulo na mesma proporção em que a empresa apresentava recordes de lucratividade em ações na Bolsa de Nova lorque. Para saber mais, acessar reportagem de Carta Capital "Da Cantareira para a bolsa de Nova lorque" de Fábio Serapião (21/10/2014). Acessível pelo link http://www.cartacapital.com.br/blogs/blog-do-serapiao/do-cantareirapara-a-bolsa-de-nova-york-976.html . Também na Revista Exame em reportagem intitulada "SABESP é generosa com acionistas, mas não com investimentos", de Maria Luiza Figueiras, em 24/11/2014. Acessível
} 
Essa lógica que prioriza ganho de capital no meio especulativo em detrimento da existência de investimentos produtivos factuais, é um dos cenários que cada vez mais se universaliza no campo da produção do urbano. Algo semelhante pode ser associado (com as características específicas de cada setor e de suas cadeias produtivas) à produção da moradia no programa habitacional Minha Casa, Minha Vida, no qual o que menos importa é a entrega de unidades habitacionais concluídas, a despeito da integração dos "usuários" (consumidores?) pobres à rede de endividamento do sistema imobiliário financeirizado para obtenção do bem ${ }^{23}$. No entanto, a dimensão do quanto a terra passa a valorizar-se, dessa vez sob o caráter especulativo, é algo imperativo nos processos de remoção e de orientação dos investimentos, na medida em que há investimentos na terra tanto de trabalho passado quanto de fatores especulativos locacionais para os fluxos de capitais e, especialmente, mercantis em territórios centrais e de escoamento, como zonas portuárias. O colapso na produção de valor refere-se ao quanto, a despeito do que é produzido incessantemente, há possibilidades de consumo e de absorção da mercadoria.

\section{CONSIDERAÇÕES FINAIS OU COMO SE TORNA INOFENSIVA A PERSPECTIVA DE DIREITO À CIDADE NA SUA FORMA ATUAL...}

O ensaio em questão procurou trazer elementos contemporâneos relevantes para se pensar a funcionalidade da produção do urbano a partir dos anos 2000 no Brasil, em contexto de crise estrutural do Capital, refletindo sobre o que aparece como uma dissociação entre direitos como pleitos políticos e lugar da política pública nas mediações das relações sociais. Essa leitura considerou tanto pressupostos como consequências impostas pela absoluta generalização da financeirização da vida em condições propícias nesse modelo "civilizatório", considerando aí os movimentos de uma sociabilidade subordinada à dinâmica do valor. O fizemos por esse caminho,

pelo link http://exame.abril.com.br/revista-exame/edicoes/1078/noticias/nao-da-nem-para-racionar. Acessos em 10/04/2016.

23 Aqui cabe a leitura de Fix (2011) a partir de estudo sobre a crise imobiliária norte-americana, com configurações históricas de mercado bastante distintas da realidade brasileira, mas que nos permite refletir sobre uma tendência no processo de produção espacial em contexto de crise estrutural. Para a autora "a passagem da produção rentista para a promoção imobiliária, centrada no incorporador, é a expressão desse processo de configuração do circuito pelo lado da oferta da moradia. A estrutura de oferta não será concentrada - poucas empresas com uma fatia grande do mercado - como em outros ramos da economia, que deram origem às grandes corporações, ao menos até os anos 1990, quando as fusões e aquisições fazem avançar o processo de concentração e centralização de capital. Será, porém, dominada pela máquina imobiliária do crescimento, expressão utilizada por dois sociólogos norte-americanos, Logan e Molotch, para descrever as coalizões - inicialmente locais - entre incorporadores e seus parceiros no governo, na mídia e no setor financeiro" (2011, p. 213). 
na medida em que a dinâmica que engendra e norteia o desenho das políticas públicas é cada vez mais tensionada pela crise estrutural de produção do valor e pela busca desesperada de extração do mesmo.

Assim, a necessidade de situar elementos importantes - porém datados - para leituras sobre a formação do urbano industrial no século XIX, no coloca face a face com os tempos atuais de hegemonia financeira e de acumulação cada vez mais predatória, consideramos relevante entender o que conduz na origem essa formação social para caminhos de colapso, aparentemente ilustrados pela ideia do absurdo. Aparenta-nos ser a realidade na modernidade algo muito mais próximo da situação de Sísifo - do que da crença racional iluminada de tempos com alguma coerência e forma sistêmica.

Essa talvez seja uma questão de inflexão e chave para a reflexão. Na constituição de um mundo no qual a autonomização da mercadoria para além do que nos sociabiliza, fortalecida em seu caráter especulativo e como algo que move engrenagens financeiras como pressuposto e acima de vinculação com seus valores de uso, a questão da produção territorial do espaço urbano e as lutas e embates de resistências e denúncias de violações de movimentos sociais e sujeitos violados, passa a vivenciar desafios profundos que os impele a pensar seus horizontes para além do pleito de acesso à riqueza socialmente produzida, da partilha da ideia de crescimento. Jappe (2013) alerta para o quanto "a crítica do crescimento só tem sentido quando está ligada a uma análise do dinamismo inerente ao valor, bem como da crise ao rumo à qual esse dinamismo inevitavelmente conduz" (p.146). Portanto, se feita de forma totalmente adversa da mediação por instrumentos que se constituíram para assegurar a institucionalidade capitalista.

Para a grande maioria da população, que passa ao largo de qualquer participação ou referência à dinâmica financeirizada do capital, o acesso aos parcos benefícios do que é produzido para fins especulativos torna-os, de forma perversa, periférica e utilitária, uma ruela dispensável da engrenagem.

Um dos aspectos centrais hoje, talvez seja refletir sobre a crença cega no topo da montanha como horizonte, se o caminho percorrido e a paisagem do entorno nos mostram o absurdo da tarefa, tal e qual Sísifo. Essa mirada ao horizonte coloca do mesmo lado sujeitos que não possuem as mesmas condições nem interesses, mas que creem no planejamento e no normativo como elementos organizadores da vida social, os quais lhe podem conferir eficácia. Não tratamos de uma questão moral, muito menos não consideramos que há um problema de 
"vontade política". Não sabemos sequer aonde chegaremos, - como, na realidade, nunca se soube na História -, por isso a importância de romper com o que modela esse percurso.

$\mathrm{Na}$ forma como essa sociabilidade se organiza - com mecanismos liberais das políticas públicas cada vez mais hegemonizadas e direcionadas pela produção do valor como fundamento dessa sociabilidade, mesmo chegando ao seu limite crítico de extração do valor -, justifica os ajustes em torno de instrumentos que permitam a integração e o acesso pela lógica da produção do valor.

Por esse caminho único não faremos com que, de fato, se subverta a noção de direito e tampouco foque-se no sujeito que é explorado e violado (e não a sua figura universal) como centralidade da vida social. A mudança dessas práticas de forma essencial, efetivamente crítica e radical necessita ser realizada antes com base em leitura crítica do que se construiu, e, então como forma de resistência e subversão, não de adesão.

\section{BIBLIOGRAFIA}

ARANTES, Otilia Beatriz Fiori. Uma estratégia fatal. A cultura nas novas gestões urbanas. In A cidade do pensamento único: desmanchando consensos. ARANTES, Otilia; VAINER, Carlos; MARICATO, Ermínia. Petrópolis, RJ: Vozes, 2012.

ARANTES, Pedro Fiori e FIX, Mariana. Minha Casa, Minha Vida', o pacote habitacional de Lula. Acessível em http://web.observatoriodasmetropoles.net/download/gthab/text_ref_outros/fix_e_arantes_MCM V.pdf

ARRETCHE, Marta Teresa da Silva. Estado federativo e políticas sociais: determinantes da descentralização. Rio de Janeiro: Revan; São Paulo: FAPESP, 2000.

ARRIGHI, Giovanni. O longo século XX: dinheiro, poder e as origens de nosso tempo. Rio de Janeiro: Contraponto; São Paulo: Editora UNESP, 1996.

CAMUS, Albert. O mito de Sísifo - ensaio sobre o absurdo. Exilado dos Livros - Le livros. Pdf. Acessível em http://lelivros.online/?s=o+mito+de+s\%C3\%ADsifo+ Acesso em 02.04.2016.

COSTA, Maria de Fatima Tardin. Ideologia e utopia no ocaso da Reforma Urbana no Brasil / Maria de Fátima Tardin Costa. - 2012. Tese de doutorado. Instituto de Psicologia. Universidade Estadual do Rio de Janeiro (UERJ).

COSTA, Silvano S.; RIBEIRO, Wladimir Antonio. Dos porões à luz do dia. In HELLER, Leo; CASTRO, José Esteban de. Políticas Públicas e gestão dos serviços de saneamento. Belo Horizonte: Editora UFMG; Rio de Janeiro: Fiocruz. 2013. 
Déficit habitacional no Brasil 2013: resultados preliminares. Nota técnica. Fundação João Pinheiro. Belo Horizonte, 2015. Acessível em http://www.fjp.mg.gov.br/index.php/docman/cei/deficithabitacional/596-nota-tecnica-deficit-habitacional-2013normalizadarevisada/file

FERNANDES, Florestan. O desafio educacional. São Paulo: Cortez editora, 1989.

FIX, Mariana de Azevedo Barretto. Financeirização e transformações recentes no circuito imobiliário no Brasil. Campinas: SP, 2011. Tese de doutorado, Universidade Estadual de Campinas.

HELLER, Leo; BASTOS, Rafael K X; Heller, Pedro G. B.; TEIXEIRA, Julio C. A experiência brasileira na organização dos serviços de saneamento básico. In HELLER, Leo; CASTRO, José Esteban de. Políticas Públicas e gestão dos serviços de saneamento. Belo Horizonte: Editora UFMG; Rio de Janeiro: Fiocruz. 2013.

JAPPE, Anselm. Crédito à morte - a decomposição do capitalismo e suas críticas. São Paulo: Hedra, 2013.

KURZ, Robert. Os últimos combates. Petrópolis, RJ: Editora Vozes, 1998.

LEFÈBVRE, Henri. A revolução urbana. Belo Horizonte: Ed. UFMG, 2008.

LOCKE, John. Segundo tratado do governo civil. Pertópolis, RJ: Editora Vozes. Organização: Igor César F. A. Gomes. Distribuição: Clube do Livro Liberal. s/d Acessível em http://www.xr.pro.br/IF/LOCKE-Segundo_tratado_Sobre_O_Governo.pdf

LÖWY, Michel e SAYRE, Robert. Revolta e melancholia. O romantismo na contracorrente da modernidade. São Paulo: Boitempo, 2015.

MARX, Karl. Gründrisse: manuscritos econômicos de 1857-1858: esboços da crítica da economia política. São Paulo: Boitempo; Rio de Janeiro: Ed. UFRJ, 2011.

MENEGAT, Marildo. Estudos sobre ruínas. Rio de Janeiro: Revan, 2012.

MÉSZAROS, István. O desafio e o fardo do tempo histórico. São Paulo, Boitempo, 2007.

NISBERT, Robert. Historia de la idea de progreso. Barcelona, Espanha: Gedisa Editorial, 1996.

OLIVEIRA, Francisco de. Crítica à razão dualista. O Ornitorrinco. São Paulo: Boitempo Editorial, 2013.

POLANYI, Karl. A grande transformação: as origens de nossa época. Rio de Janeiro: Campus, 2000.

VAINER, Carlos B. Cidade de Exceção: reflexões a partir do Rio de Janeiro. (s/d) Acessível em http://pfdc.pgr.mpf.mp.br/atuacao-e-conteudos-de-apoio/publicacoes/direito-a-moradiaadequada/artigos/cidade-de-excecao-carlos-vainer Acesso em 01.04.2016. 
VAINER, Carlos Bernard. Pátria, empresa e mercadoria. In A cidade do pensamento único: desmanchando consensos. ARANTES, Otilia; VAINER, Carlos; MARICATO, Ermínia. Petrópolis, RJ: Vozes, 2012.

WACQUANT, Löic. Punir os pobres. A nova gestão da miséria nos Estados Unidos (A onda punitiva). Rio de Janeiro: Revan Editora. Instituto Carioca de Criminologia, 2007.

Trabalho enviado em 18 de abril de 2016.

Aceito em 05 de julho de 2016. 